\title{
Yet More Insights on the Petrogeophysics of Pre-salt Rocks from Brazil
}

\author{
Guilherme F. Vasquez, Marcio J. Morschbacher, Julio C.R. Justen, Elita S. de Abreu, Camila W. Ramnani, Vanessa
}

Madrucci, Yaro M.P. Silva, Julice F. Santos and Sylvia M. C. dos Anjos, Petrobras

Copyright 2021, SBGf - Sociedade Brasileira de Geofísica

This paper was prepared for presentation during the $17^{\text {th }}$ International Congress of the Brazilian Geophysical Society held in Rio de Janeiro, Brazil, 16-19 August 2021.

Contents of this paper were reviewed by the Technical Committee of the $17^{\text {th }}$ International Congress of the Brazilian Geophysical Society and do not necessarily represent any position of the SBGf, its officers or members. Electronic reproduction or storage of any part of this paper for commercial purposes without the witten col the Brazilian Geophysical Society is prohibited.

\section{Abstract}

The Pre-salt exploration revealed some world class giant fields, with relatively light oil, with variable amounts of $\mathrm{CO}_{2}$. Production reports for the Pre-salt justify the importance of this oil province not only for Brazil, but also for the international oil market. In this paper we intend to update some of our insights regarding the petro elastic behavior of the rocks from Pre-salt Santos Basin, with legacy and new, unpublished data. We show some examples of the effect of composition on the elastic-wave velocities of reservoir rocks and the application of different rock physics models for rock samples and well logs.

\section{Introduction}

In November 2020, after 12 years from the first oil, the Presalt production was 1.92 millions of barrels of oil per day, and 2.42 millions of barrels of oil equivalent per day. The top six producers averaged around $50000 \mathrm{BBE} /$ day each in middle 2020 (PPSA, 2020). For comparison issues, the total production from the 85 fields from Reconcavo Basin, the most prominent mature basin in Brazil, was around 62000 BBE/day (ANP, 2020).

The deposition of the Pre-salt sequence begun with the break-up of the Gondwana supercontinent, in the upper Valanginian/Hauterivian, and progressed until the Aptian. Generally, good reservoir facies are found in the coquinas from the Upper Syn-rift sequence and the stromatolites, grainstones and rudstones from the Sag sequence (Carlotto et al., 2017).

There are igneous rocks inside the Pre-salt sequence. Some of these igneous rocks were placed synchronous with the Pre-salt deposition, but some comprises intrusions from latter ages. Although igneous rocks may be relatively good reservoirs, especially if fractured and/or altered, we have no official information regarding steady state production from such rocks from the Pre-salt interval. In a previous work (Vasquez et al., 2019b) we discussed aspects of the petro elastic behavior of the igneous rocks in the Pre-salt interval.

The Pre-salt carbonates presents some compositional variations (Souza et al., 2018). Calcite, dolomite and quartz may represent more than $95 \%$ of the total average rock composition. There are no doubts about the importance of clay minerals among the other secondary minerals present in the Pre-salt.

In a previous paper we discussed the effect of composition on the elastic properties of the Pre-salt reservoir rocks. Our aim here is to revisit these discussions and comment some other aspects of the petrogeophysics of the Pre-salt rocks from Santos basin.

\section{The Effect of Mg-Clay Minerals on Wave Velocities}

We had discussed the effect of magnesium-rich clays on the petroacoustic behavior of the Pre-salt rocks (Vasquez et al., 2019a). Since then we collect more data from different rocks, including whole-core plug samples and sidewall cores. Figure 1 shows scatter plots for the compressional-wave velocity $\left(V_{P}\right)$ and for the sher-wave velocity $\left(V_{S}\right)$ as a function of porosity for 148 samples from the Pre-salt from Santos Basin, with data points colored according to the amount of total clay minerals and micas (based on X-ray diffraction analysis, XRD). The blue discs corresponds to "clean carbonates", because the clay concentration is less than $1 \%$, despite the variation of calcite, dolomite and quartz (or silica) content.

The presented data corresponds to a confining stress of $27.58 \mathrm{MPa}$ and to room-dry conditions, to avoid any velocity dispersion effect. Our lab measurements indicates that Gassmann equation works well for porous reservoir rocks from the Pre-salt (Vasquez et al., 2019c) and it can be applied to simulate saturation effects.

The reader must be aware that this particular data set is biased toward relatively high clay content. These rock samples were collected in specific wells which found some clay, which is not the general case of Pre-salt wells. It might not be considered as a representative data set for the Presalt, but it is a good data set to explore the effect of clay minerals on the elastic properties of the Pre-salt rocks.

The data point scattering for the "clean" samples (fig. 1) is associated with pore-space geometry (Eberli et al., 2003; Weger et al., 2009). However, the composition has a relevant influence on the velocities: dolomite-rich samples exhibitis slightly higher velocities and quartz-rich rocks tends to show lower velocities. Moreover, when it comes to the presence of clay minerals, the velocity shows a pronounced decrease, even for small amounts of clays.

This pronounced velocity decrease with increasing clay content can represent a pitfall to interpretation, because the impedance is similar to high-porosity, good reservoir intervals. The use of two or more elastic attributes can help to reduce risks, and a good understanding of the geological context is of unquestionable importance (Dillon et al., 2015). 
We can observe a decrease in the shear-wave velocity $\left(V_{S}\right)$ with increasing amount of clay content as well, as in the analogous scatter plot in fig. $1 \mathrm{~b}$.

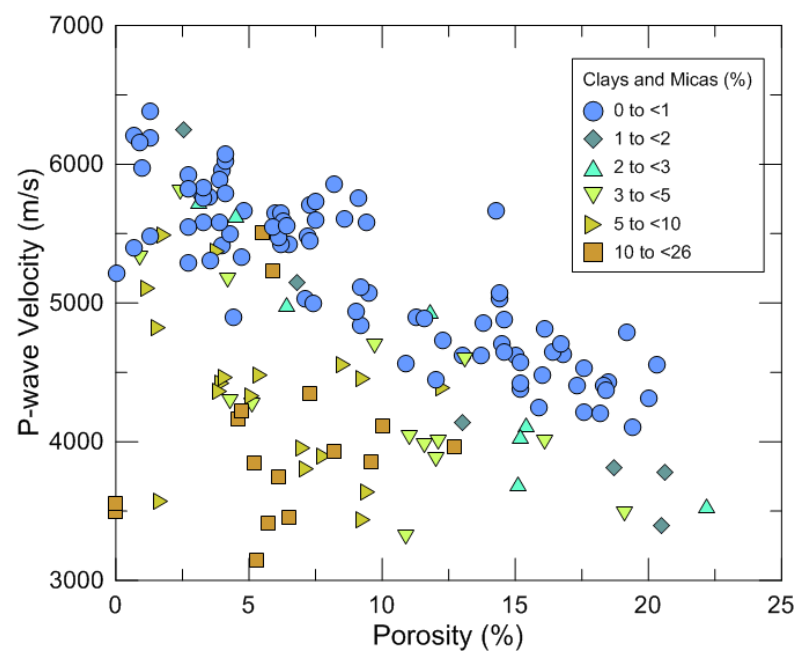

(a)

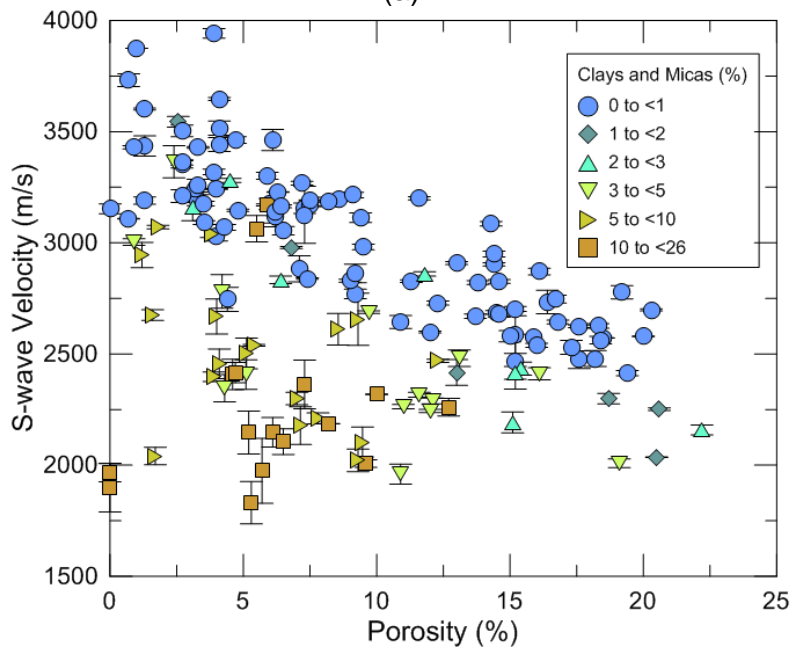

(b)

Figure 1: (a) P-wave velocity as a function of porosity for samples from several areas from the Pre-salt Santos Basin, with data points colored according to the total amount of clay minerals and micas. (b) Same plot for Swave velocity. Data point are located at the average $V_{s}$ value and the bars spams from the "slow" to the "fast" $V_{S}$ values.

Figure 2 illustrates the scatter plot for the $V_{S}$ as a function of $V_{P}$ with the data points coded according to the total clay contend, for the same sample set. The continuous line in this graph corresponds to a $V_{P} / V_{s}$ ratio of 1.75 . Reference values in the literature (e.g. Mavko et al., 2020) for $V_{\mathrm{P}} / \mathrm{V}_{\mathrm{S}}$ are 1.8 for dolostones and 1.9 for limestones, for watersaturated rocks. The vertical bars are not error bars. These bars spam from the minimum up to the maximum S-wave value, and the data points are located on the average. The minimum and maximum S-waves have orthogonal polarizations.

In this figure it is interesting to note that the velocity ratio for "shaly" samples are slightly different to those from "clean" samples. Thus, the discrimination between "clean" and "shaly" reservoirs with elastic attributes may be not so easy as in sand-shale siliciclastic environments, because quartz has the lowest $V_{p} / V_{S}$ ratio among common minerals. Several "shaly" samples presents $V_{S}$ less than $2500 \mathrm{~m} / \mathrm{s}$ and $V_{P}$ less than $4500 \mathrm{~m} / \mathrm{s}$.

Another interesting feature in Figure 2 is that some "clean" samples deviates significantly from the general trend, to $\mathrm{V}_{\mathrm{P}} / \mathrm{V}_{\mathrm{S}}$ ratios lower than 1.6. These samples are rocks with large amounts of quartz ( $>33 \%)$. It is a strong evidence that elastic attributes may be used to identify quartz-rich intervals, depending on the spatial distribution and thickness.

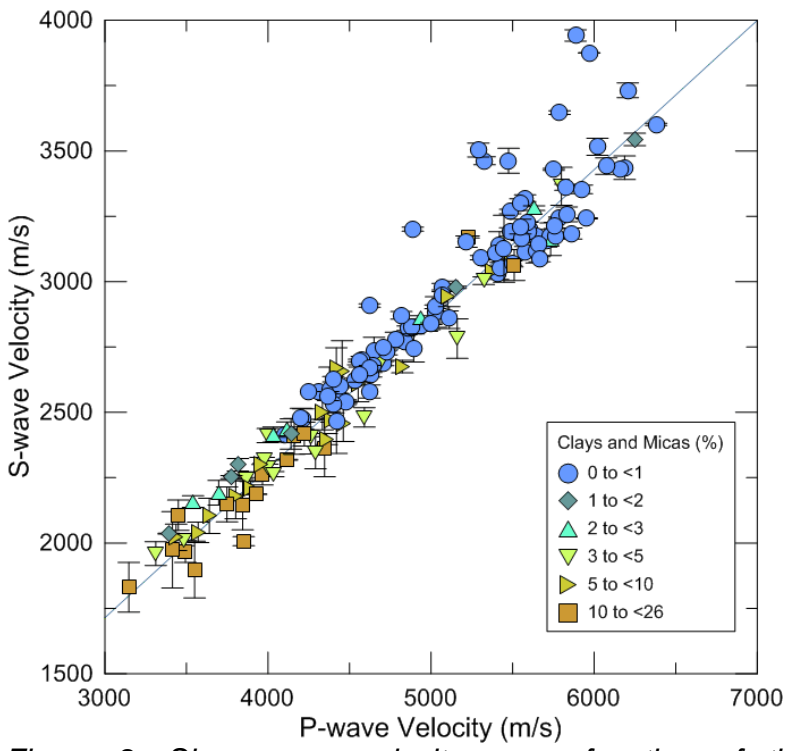

Figure 2: Shear-wave velocity as a function of the compressional-wave velocity for samples from several areas from the Pre-salt Santos Basin. The continuous line corresponds to a $V_{P} / V_{S}$ ratio of 1.75 .

\section{Petroelastic Modeling Applied in Pre-salt Rocks}

The use of rock physics models is of paramount utility for seismic and sonic log interpretation. As the rocks are heterogeneous and contains a wide variety of grain and pore geometries, it is a very complex medium, difficult to model. Thus "all models are wrong, some models are useful" (Box, 1979), and an important step in applying rock physics models is the calibration for each particular case. A well calibrated rock physics model can be used for qualitative or even quantitative inferences regarding reservoir quality.

One difficulty in quantitative modeling is the choice of the elastic properties for the mineral phases. In some cases there is a wide range of data in the literature. As an example, Table 1 list a compilation of some elastic properties of minerals from three references from the literature. In the case of some clay minerals, it is hard to find references for solid phase elastic properties. One may take advance of this ignorance using the clay properties as a "fine tuning" parameter, but it can be a dangerous procedure. 
Table 1: Elastic properties of some pure minerals: bulk and shear moduli, Poisson's ratio and density. Compiled from Wang (2000), Mavko et al. (2020) and Schön (2011). The range for Clay* comprises a variety of clay minerals, as Illite, Kaolinite, Chlorite, Smectite, Sepiolite, Kerolite, etc.

\begin{tabular}{ccccc}
\hline Mineral & $\begin{array}{c}\text { Bulk } \\
\text { Modulus } \\
\text { (GPa) }\end{array}$ & $\begin{array}{c}\text { Shear } \\
\text { Modulus } \\
\text { (GPa) }\end{array}$ & $\begin{array}{c}\text { Poisson's } \\
\text { Ratio }\end{array}$ & $\begin{array}{c}\text { Density } \\
\left(\mathrm{g} / \mathrm{cm}^{3}\right)\end{array}$ \\
\hline Calcite & $70 \pm 7$ & $30 \pm 3$ & $0.31 \pm 0.01$ & 2.71 \\
Dolomite & $83 \pm 12$ & $48 \pm 4$ & $0.25 \pm 0.05$ & 2.87 \\
Quartz & $37 \pm 0.5$ & $45 \pm 0.2$ & $0.07 \pm 0.01$ & 2.65 \\
Clay* $^{*}$ & 1.5 to 35 & 1.4 to 12 & 0.2 to 0.35 & 2.13 to 2.75 \\
\hline
\end{tabular}

We show in Figure 3 a scatter plot for the acoustic impedance as a function of porosity (for the same dataset in figs. 1 and 2, with the same symbol convention). The continuous line superimposed in the graph corresponds to realizations of the Vernik-Kachanov (2010) model for different amounts of clay minerals (0,10 and 20\%, as indicated in the figure). It can be noticed that this model can explain the effects of clay mineral on the acoustic impedances of the Pre-salt rocks.

Geological models may be combined with petroelastic modeling to reduce interpretation ambiguities and thus exploration risks.

The Vernik-Kachanov model was conceived originally to siliciclastic rocks, but had been successfully applied to carbonate rocks (Vasquez et al., 2019; Mur and Vernik, 2020). The model is based in the micromechanics of porous media and includes the effect of pore geometry using pore shape factors, which can be calibrated with laboratory measurements.

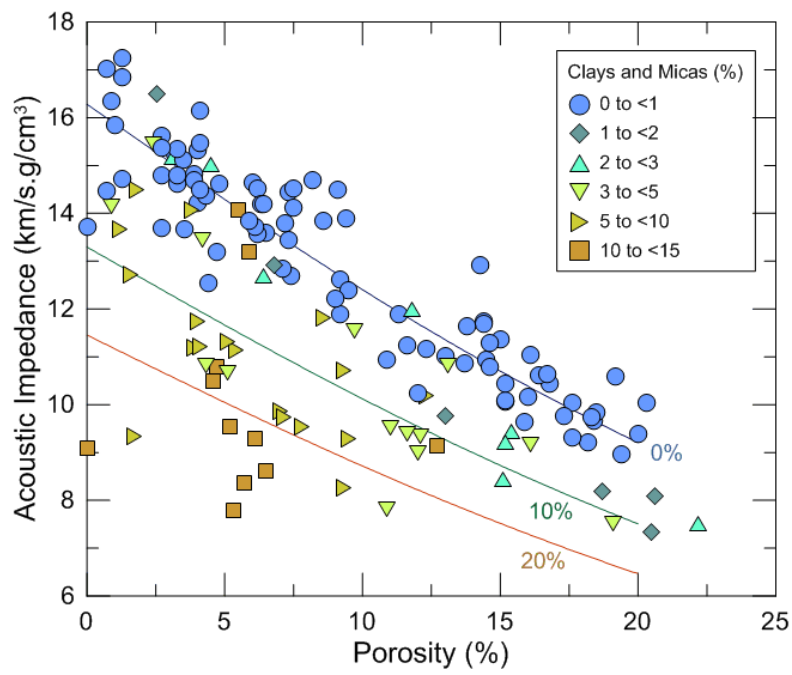

Figure 3: Acoustic impedance as a function of porosity for samples from several areas of the Pre-salt Santos Basin, with data points colored according to the total amount of clay minerals and micas. The continuous lines corresponds to realizations of the Vernik-Kachanov model for different total clay content (indicated near each curve).

Another useful rock physics model is the Stiff-Sand model (cf. Mavko et al., 2020; Dvorkin et al., 2014). This model applies the contact theory and heuristic modifications of the Hashin-Shtrikman upper bound for the elastic moduli of granular cemented sediments. Although the contact theory considers spherical grains, we can imagine that this model does not depends strongly on grain and pore geometries because of the introduction of cement. The model allows to use different properties for grain and cement.

Figure 4 illustrate a photography from a thin section of a reservoir rock from the Pre-salt from Santos Basin. The geometry or texture of this rock resembles a granular cemented material. Thus it is reasonable to apply the StiffSand model to these rocks.

One example of the performance of the Stiff-Sand model in Pre-salt carbonate rocks is illustrated in Figure 5. This figure shows a simplified compositional model, restricted to calcite, dolomite, quartz and clays, as well as density, $V_{P}$ and $V_{P} / V_{S}$ ratio logs. Original log data are in black and the model predictions in blue. There is a good agreement between data and model.

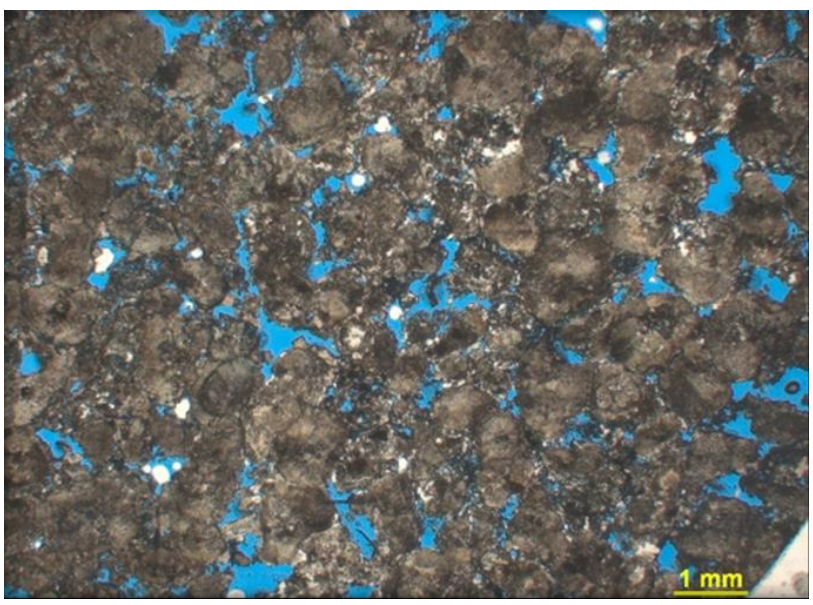

Figure 4: Thin section photograph from a reservoir rock from Santos Basin Pre-salt. The geometry of this particular rock resembles a cemented granular media.

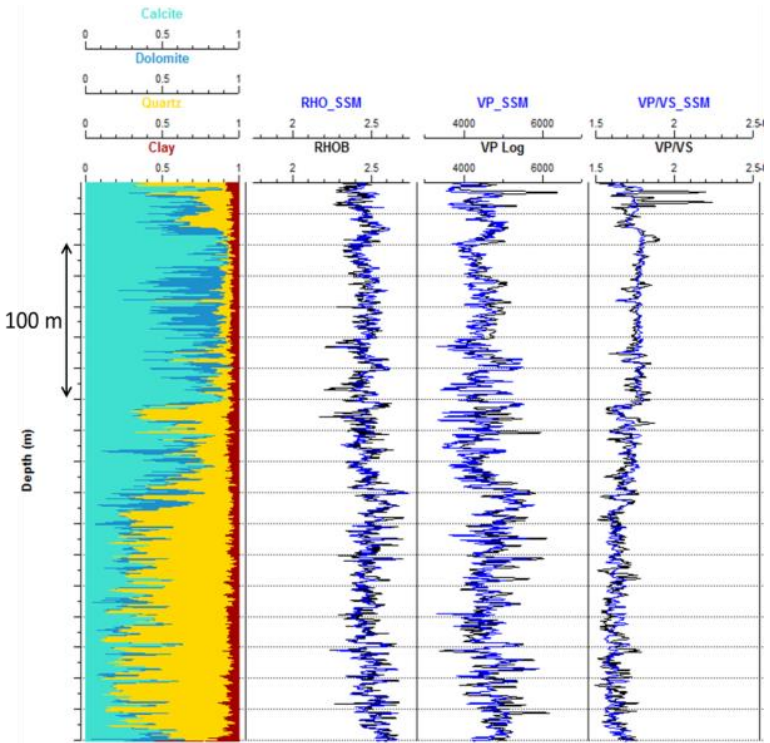

Figure 5: Compositional log (left track), density, $P$-wave $V$ elocity and $V_{P} / V_{S}$ ratio logs with realizations from the StiffSand model. Original elastic log curves are in black, and modeled curves are in blue. 
Inclusion models are usually very popular for carbonate rocks (Abreu, 2010). In Effective Media models, pores of some defined geometry are added mathematically to the solid matrix phase. The pore shape in these models is generally represented by the aspect ratio of ellipsoidal pores (the ratio between the minor and maximum axis). In the Differential Effective Media (DEM, cf. Berrymann, 1995), the pores are added in very small, differential, amounts, in an iterative scheme. At each iteration the "mixture" solid matrix plus pores is considered as the background media, then a tiny amount of pore is added, until we reach the desired porosity.

In Figure 6 we illustrate the result of a realization of the Differential Effective Media (DEM) for a constant aspect ratio value. In this example there are some local deviations between model and data curves, which can be minimized adjusting the aspect ratio, for instance.

In Figure 7 we reproduce a thin section photograph from a particular reservoir rock from Pre-salt, which pore space suggest the occurrence of different pore sizes as well as different pore shapes. Although not perfectly ellipsoidal, evidently, there are some elongated pores that may be suitable to model according to the aspect ratio scheme.

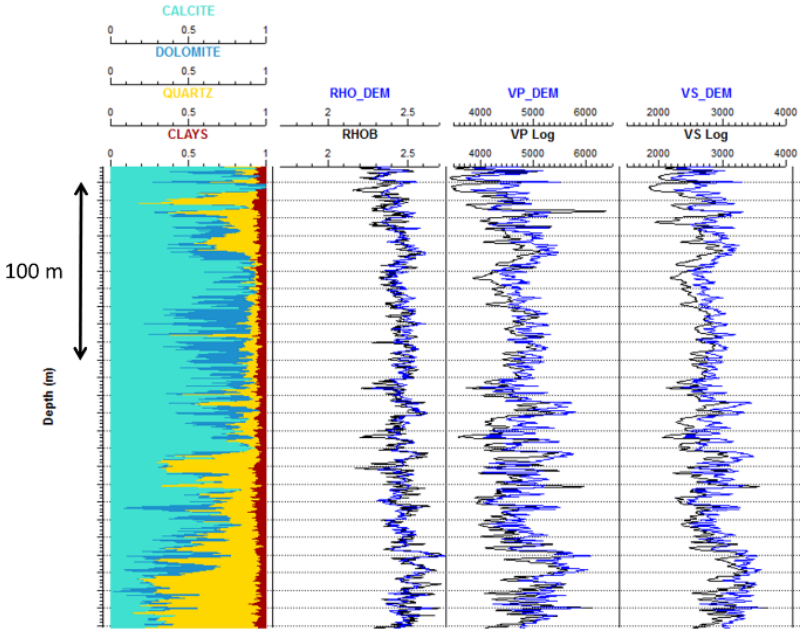

Figure 6: Compositional log (left track), density, $P$-wave Velocity and $S$-wave Velocity logs with realizations from the Differential Effective Media (Berrymann, 1995) for a constant aspect ratio value (0.7). Original elastic log curves are in black, and modeled curves are in blue.

\section{Revisiting the Velocity Deviation Log}

The Stiff-Sand Model (SSM) does not take the pore geometries into account, but can be applied to Pre-salt rocks with relative success for velocity and impedance estimations.

Anselmetti and Eberli (1999) proposed a simple and innovative approach to obtain information of dominant pore type in carbonate rocks based on the Willy time-average equation, and the sonic and density (or neutron) logs. This ingenious technique is the so called velocity deviation log. The authors successfully applied their method in some datasets and discussed some cases in which there was some caveats, and why this may occur.
Based on observation of deviations from the estimates made with the SSM relative to real data, we made some exercises in order to check if these departures could be related to pore geometry or pore type.

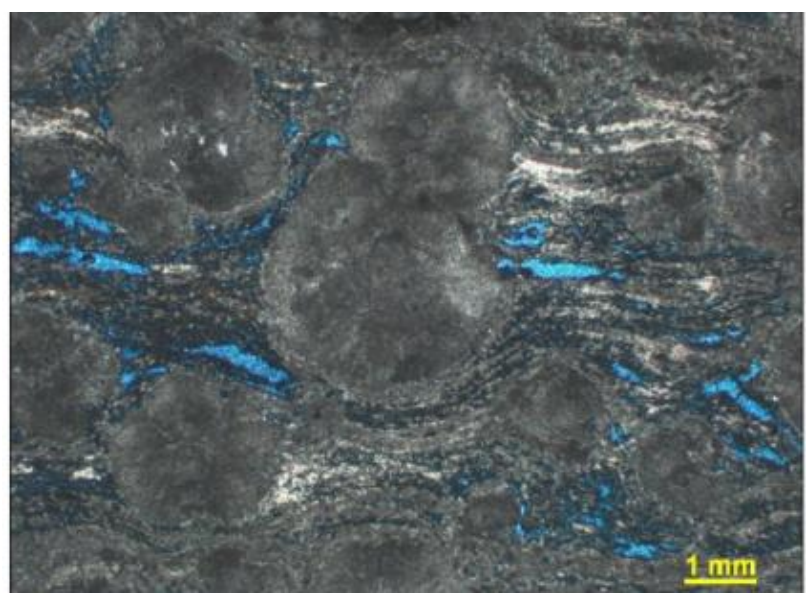

Figure 7: Thin section photograph for a reservoir rock from the Pre-salt. It is interest to note that the pores are not strictly similar to ellipses, but there are several elongated pores, as well as micropores of different shapes.

Figure 8 illustrate a panel with the dominant composition of a wide data set from 85 core plugs sampled in a Pre-salt well, SX-7A, distributed in a $196 \mathrm{~m}$ depth interval. We used this case as our first exercise because of the significant amount of compositional and elastic-wave velocity data. Moreover, the main composition comprises only three minerals (calcite, dolomite and quartz).

We applied the Stiff-Sand Model to this data set, considering only the three dominant mineral, with renormalized relative volumetric composition and compared to real laboratory $\mathrm{P}$-wave and $\mathrm{S}$-wave velocity measurements. The deviation of the predictions for the velocities, as well as on the bulk and shear modulus were compared with the basic petrophysical data (porosity and permeability) and complemented with thin section photographs observations.

We observed that, in general, rocks which velocity data points are above the identity line (the model prediction are higher than the observed velocity value) are dominated by micropores and presents lower absolute permeability values. On the other hand, rocks which data points are below the identity line (measured velocity higher than the model prediction) exhibits significant amounts of large and relatively rounded pores, and tends to present higher permeabilities.

Figure 10 reproduces two photographs from thin sections prepared with rocks from the well SX-7A. The rock corresponding to fig. 10(a) the model prediction is about $8 \%$ higher than the measured $\mathrm{P}$-wave velocity $\left(\mathrm{V}_{\mathrm{S}}\right.$ error is similar), and is obviously dominated by small pores (with porosity of $2.77 \%$ and permeability of $0.24 \mathrm{mD}$ ). For the rock corresponding to fig. 10(b), the model prediction for $\mathrm{P}$ wave velocity is around $9 \%$ lower than the observed value ( $V_{S}$ around $7 \%$ lower). Although there are some small pores, this rock is dominated by relatively medium to large 
pores (with porosity equal to $22.8 \%$ and permeability to 408 $\mathrm{mD})$.

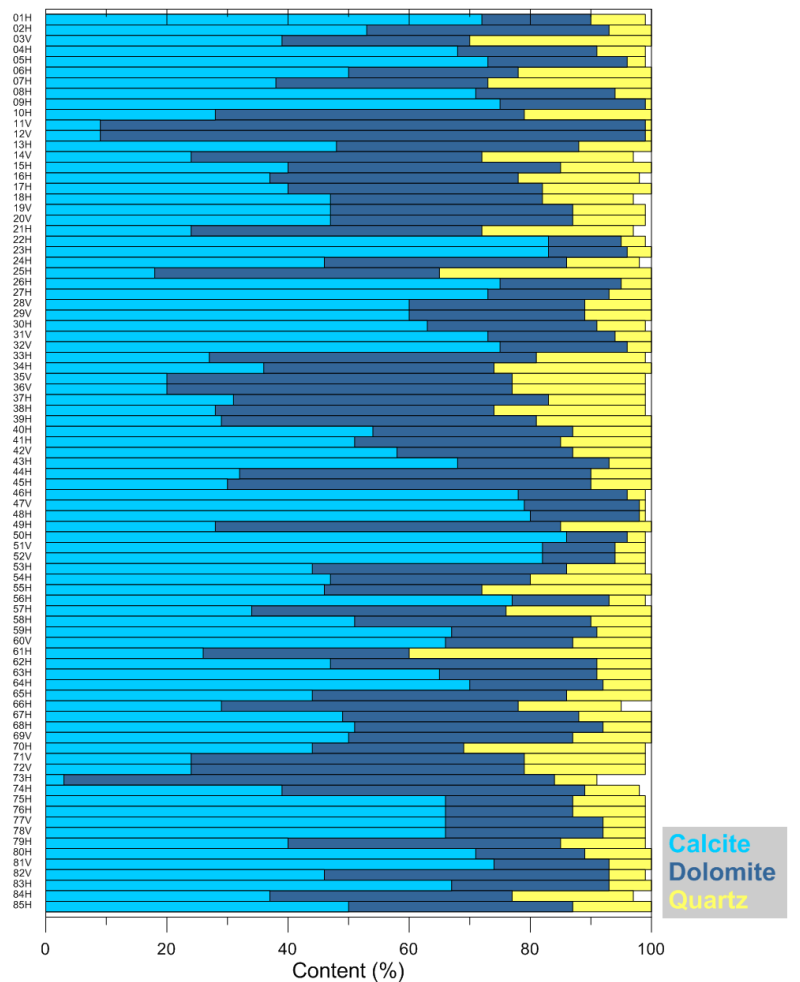

Figure 8: Dominant composition of 85 samples from well SX-7A, with relative amounts of Calcite (blue), Dolomite (red) and Quartz (orange).

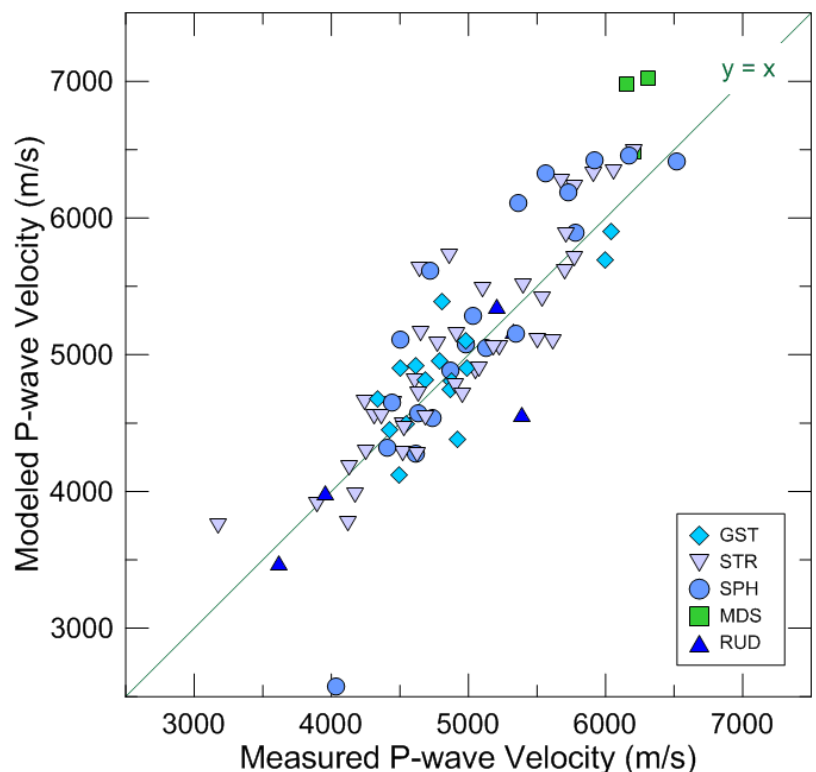

Figure 9: Compressional-wave velocity modeled with the Stiff Sand model and measured in the laboratory (for dry rocks from the well SX-7A at a pressure of $27.58 \mathrm{MPa}$ ) with the data points indicating the facies (GST=Grainstone, STR=Stromatolite, $S P H=$ Spherulitite, MDS=Mudstone, $R U D=R u d s t o n e)$. The continuous line corresponds to a perfect prediction.

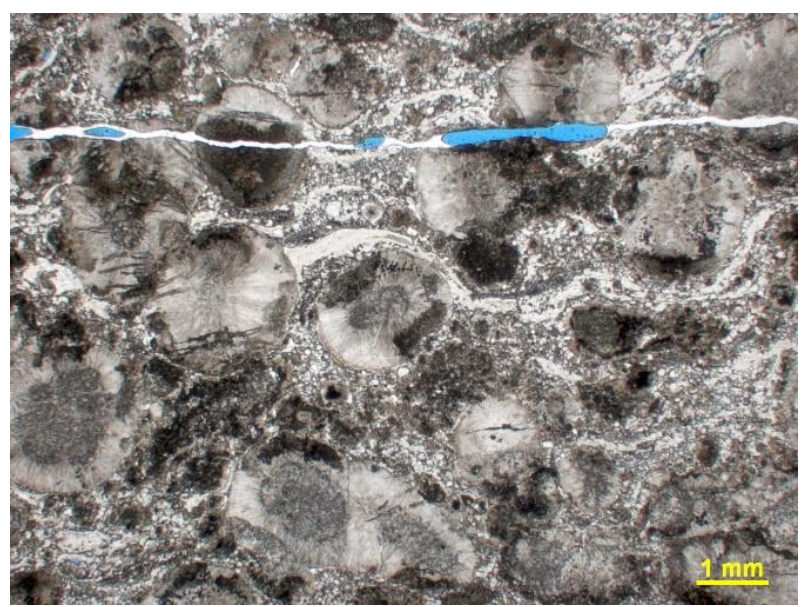

(a)

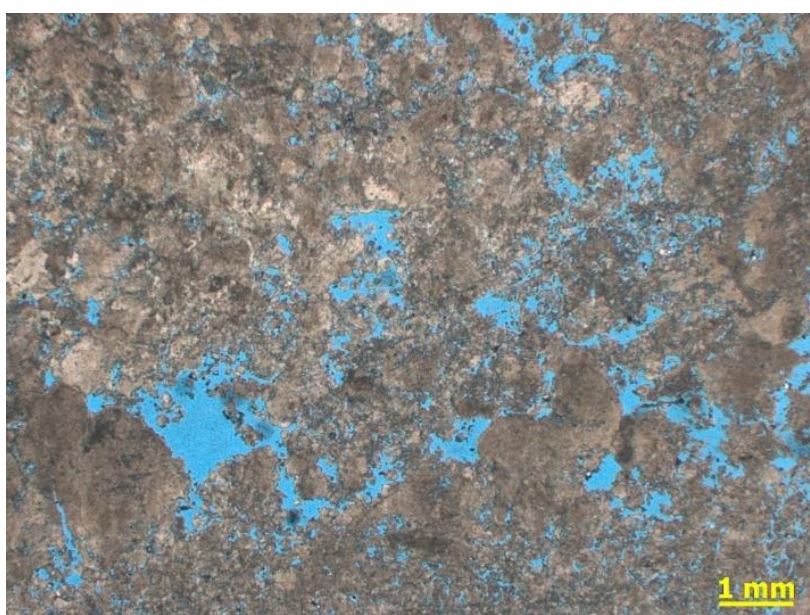

(b)

Figure 10: Examples of photographs from thin sections from rocks sampled at the well $S X-7 A$. For the rock spherilitites with Mg-clay in (a) the model prediction for $P$ wave velocity is $8 \%$ higher than the laboratory observation. For the rock grainstone in (b) the laboratory measurement of $P$-wave Velocity is $9 \%$ higher than the model prediction.

Few exceptions were observed, and these amazing results encourage us to a deeper investigation of this possible application of the Stiff-Sand model, inspired on the Velocity Deviation Log.

\section{Conclusions}

We presented new data on the petro elastic behavior of Pre-salt rocks, which are in good agreement with previously released data.

Some alternative tools to model and interpret the velocity and impedance of Pre-salt rocks were presented and briefly discussed. Three prominent tools are the Stiff-Sand, the Vernik-Kachanov and the Differential Effective Media models. Each one has its advantages and weakness, which depends on the desired application. It is possible to obtain good estimates with all these models with an adequate calibration. 
Moreover, an initial investigation of some models deviation and its relationship with rock pore geometry and permeability, that seems to be very promising, was illustrated.

\section{Acknowledgments}

We thanks Petrobras for the permission to publish this paper. Special thanks for our colleagues and friends, including managers, geologists and geophysicists from Exploration and from the Research Center that are supporting and enriching our studies.

\section{References}

ANP, 2020. Boletim da Produçao de Petróleo e Gás Natural, Agencia Nacional de Petróleo. http://www.anp.gov.br/arquivos/publicacoes/boletinsanp/producao/2020-01-boletim.pdf

Anselmetti, F.S., and Eberli, G.P. 1999. The VelocityDeviation Log: A Tool to Predict Pore Type and Permeability Trends in Carbonate Drill Holes from Sonic and Porosity or Density Logs. AAPG Bulletin, 83, 450-466.

Berrymann, J.G. 1995. Mixture Theories for Rock Properties. In: AGU Reference Shelf 3: Rock Physics and Phase Relations, A Handbook of Physical Constants, 205228.

Box, G.E.P. 1979 Robustness in the Strategy of scientific model building, in Launer, R.L.; Wilkinson, G.N (eds), Robustness in Statistics. Academic Press, pp. 201-236. ISBN 9781483263366.

Carlotto, M.A., da Silva, R.C.B. Yamato, A.A., Trindade, W.L., Moreira, J.L.P., Fernandes, R.A.R., Ribeiro, O.J.S. et al., 2017, Libra: A newborn giant in the Brazilian Presalt Province, in R.K. Merrill and C. A. Sternbach (eds.), Giant fields of the decade 2000-2010: AAPG Memoir 113, 165176.

Dillon, L.D.; Schwedersky Neto, G.; Nunes, C. 2015. Rock Physics: Key for Quantitative Interpretation in Carbonates. Brazilian Petroleum Conference - Carbonates - May 2015 - Rio de Janeiro - Brasil.

Dvorkin, J., Gutierrez, M.A. and Grana, D., 2014. Seismic Reflections of Rock Properties. Cambridge University Press, Cambridge, UK.

Eberli, G.P., Baechle, G.T., Anselmetti, F.S., Incze, M.L. 2003. Factors controlling elastic properties in carbonate sediments and rocks: The Leading Edge, 22, 654-660.

Mavko, G., Mukerji, T. and Dvorkin, J., 2020. Rock Physics Handbook, 3rd Ed. Cambridge University Press, Cambridge, UK. ISBN: 9781108420266

Mur, A., and Vernik, L. 2020. Rock physics modeling of carbonates. SEG Technical Program Expanded Abstracts, 2479-2483. DOI:10.1190/segam2020-3427703.1

PPSA, 2020. Pré-Sal Petroleo S.A. O pré-sal em números. https://www.presalpetroleo.gov.br/ppsa/o-pre-sal/o-presal-em-numeros (acessed in February, 2021).

Souza, R. S., L. M. Arienti, S. M. Viana, L. C. Falcão, M. A. Cuglieri, R. P. Silva Filho, C. O. Leite, et al., 2018, Petrology of the hydrothermal and evapotitic continental
Cretaceous (Aptian) pre-salt carbonates and associated rocks, South Atlantic Santos Basin, offshore Brazil: Presented at the 2018 Annual Convention and Exhibition, AAPG.

Vasquez, G.F., Morschbacher, M.J., dos Anjos, C.W.D., Silva, Y.M.P., Madrucci, V., and Justen, J.C.R., 2019a. Petroacoustics and composition of presalt rocks from Santos Basin, The Leading Edge, 38, 342-348. https://doi.org/10.1190/tle38050342.1

Vasquez, G., Morschbacher, M., Ruthner, M., Silva, Y., Carmo, I., Ferreira, J., dos Anjos, C., Madrucci, V., and Justen, J. 2019b. Petrogeophysics of the Brazilian pre-salt rocks. SEG Technical Program Expanded Abstracts, 37133717. https://doi.org/10.1190/segam2019-3214492.1

Vasquez, G.F., Morschbacher, M.J., and Justen, J.C.R. 2019. Experimental efforts to access 4D feasibility and interpretation issues of Brazilian presalt carbonate reservoirs. Interpretation, 7, SH1-SH18. https://doi.org/10.1190/INT-2018-0203.1

Vernik, L., and Kachanov, M. 2010. Modeling elastic properties of siliciclastic rocks: Geophysics, 75, no. 6, E171-E182, https://doi.org/10.1190/1.3494031.

Vernik, L., 2016. Seismic Petrophysics in Quantitative Interpretation. Investigations in Geophysics 18. Society of Exploration Geophysicists. Tulsa, OK. 226 p. https://doi.org/10.1190/1.9781560803256

Wang, 2000. The Gassmann Equation Revisited: Comparing Laboratory Data with Gassmann's Predictions. In: Seismic and Acoustic Velocities in Reservoir Rocks: Recent Developments (Geophysics Reprint Series No. 19) Nur, A.M and Wang, Z. (eds). Society of Exploration GEophysisicsts. Tulsa. OK. ISBN-13: 978-1560800880 ISBN-10: 1560800887

Weger, R.J., Eberli, G.P., Baechle, G.T., Massaferro, J.L. and Sun, Y-F. 2009. Quantification of pore structure and its effect on sonic velocity and permeability in carbonates: AAPG Bulletin, 93, 1297-1317. 